\title{
Transnational Knowledge Transfer and Innovation Based on Academic Subjects: The Patterns and Characteristics of Knowledge Transfer and Innovation by Chinese Scholars Returned from the United States Jinyu Meng ${ }^{1, a}$, Xiangdong Chen ${ }^{1, b}$
}

\author{
${ }^{1}$ School of Economics and Management, Beihang University, Beijing, China, 100191 \\ askyforest@163.com, bchenxdng@126.com
}

\begin{abstract}
Keywords: returned scholar, transnational knowledge transfer, knowledge innovation, similarity of keywords, academic subjects

Abstract. The return of overseas talents, in particular high-level overseas talents, could bring advanced theories, knowledge, technologies and experiences back to China, which, therefore, may be deemed an important channel of transnational knowledge transfer and innovation. With emphasis on high-level scholars who have returned from the U.S. and are working in top universities and research institutions in China, this paper has investigated issues regarding transnational knowledge transfer and innovation as a result of their returning to China based on the similarity and continuity of their research subjects. Specifically, Academic subjects are identified with keywords in papers. And according to the amount of similar keywords, patterns of knowledge transfer and innovation are classified into three different types, which are named study-type innovation, leading-type innovation and breakthrough-type innovation. The statistical results show that leading-type innovation has the largest number among these three modes. And the research quality of study-type innovation and leading-type innovation is much better than the quality of breakthrough-type innovation in most cases. The results prove that today the transnational knowledge transfer has been growing more important in pushing knowledge innovation made by scholars returned from overseas.
\end{abstract}

\section{Introduction}

As increasing Chinese talents return from overseas to their motherland, China has gradually changed from a country characterized by brain drain to the one attracting talents who study overseas back home. After entering into the 21 st century, returned talents and scholars raised from 9121 in 2000 to 364,000 in 2014, up by nearly 40 times, according to the Ministry of education. Scholars returning to China totaled at 1.81 million as of 2014 , accounting for $74.48 \%$ of total students studying abroad. These Chinese talents returning from overseas have made important contributions to economic progress as well as scientific and technological development of China.

Researches have showed that the flow of human capital is an important channel of knowledge transfer. Fosfuri (2001) studied the technology spillover and transfer via human capital flow, finding that personnel who used to work in foreign-owned enterprises would improve the productivity of domestic enterprises when they were getting employed [1]. Williams (2007) also believes that transnational flow of talents has accelerated the spread of knowledge and technology globally [2]. Trippl (2011) defines flowing scientific and technical personnel as knowledge spillover agents, as they lead to significant knowledge spillover effect and thereby advancing regional innovation [3]. Nan Xuguang (2009) points out that the flow of high-level scientific and technological personnel is vital to the transfer and spillover of knowledge cross regions [4].

Overseas talents, in particular high-level overseas talents, are typical international scientific and technological immigrants. Their return can bring advanced theory, knowledge, technology and experience back to China, which, therefore, may be deemed an important channel of transnational knowledge transfer and innovation. Commander (2004) holds that scholars returning from overseas get access to better education resources and accept better scientific training, so their return can increase the stock of human capital and is favorable to economic development of their motherland [5]. Santos (2003) also believes that returned scholars promote technology spillovers and the 
accumulation of knowledge of their motherlands [6]. Zucker (2006) performed tracking investigation to 5401 star scientists from 25 countries, concluding that these scientists and their knowledge are catalyst for scientific and technological innovation as well as economic development, and play an important role in promoting academic and industrial innovation of receiving country [7]. Dai (2009) [8], Liu (2010) [9] and Filatotcheva (2011) [10] study returnee entrepreneurs, demonstrating that enterprises established by returnees are more innovative than local enterprises due to their international vision and experience. In addition, returnee entrepreneurs can help to improve the innovation of local enterprises through knowledge transfer and spillover. Therefore, it is of great practical and guiding significance to study the patterns and characteristics of transnational knowledge transfer and innovation of returned talents and scholars.

In this paper, we performed investigation to scholars of Tsinghua University, Beijing University, Fudan University, Chinese Academy of Sciences as well as other domestic first-class universities and research institutes who studied in the United States first and then returned back to China, to study an important channel of transnational knowledge transfer and innovation by these returned scholars, i.e. introducing academic subjects from the United States to China and continuing their study, research and innovation. And based on the similarity and continuity between the research subjects they studied after returning back to China with those they studied in the United States, patterns of knowledge transfer and innovation are classified into three different types, which are named study-type innovation, leading-type innovation and breakthrough-type innovation, and characteristics of knowledge transfer and innovation of these types were also investigated. The results extend and enrich existing researches on the knowledge transfer and innovation of returned scholars.

\section{Data and methods}

(1) Data acquisition

We performed investigation to scholars who continued to engage in educational research in colleges and universities as well as research institutions as a result of graduation form universtities of the United States and returning to China. Manual query method was adopt by selecting a university or research institution, and inquiring education background of professors and associate professors one by one in home page of science and engineering departments of the univesity and research institution. Taking Fudan University as an example, professors and associate professors from Department of Computer Science, Department of Physics, Department of Materials Science, Department of Chemistry, Department of Environmental Science and Engineering, School of Life Sciences, School of Basic Medical Sciences and other science and engineering departments who used to study in the United States (with the titles of $\mathrm{PhD}$ or postdoc) were summarized. Returned scholars working in Tsinghua University, Beijing University and the Chinese Academy of Sciences who had similar experience of studying in the United States were summarized by adopting the same method. Finally 73 research subjetcs were collected through screening, who are all middle-aged or young scholars studied overseas in 1990s and majored in science and engineering.

The online research platform Web of Science ${ }^{\circledR}$ developed by Thomson Reuters Company was employed to retrive papers published by each returned scholar as of December 31, 2015. There existed a lot of difficulties to retrieve all papers publised by Chinese scholars, among which the most difficult one was to solve the problem that different authors had the same name. Web of Science ${ }^{\circledR}$ platform recorded the names of authors of most papers included before 2007 by Pinyin of the last name plus the initial of the first name. Taking YAO Hongwho is from Tsinghua University as an example, most of his papers are signed by "Yao H". He was awarded with $\mathrm{PhD}$ degree of the Stanford University, and later got engaged in postdoctoral research in Standford Universtiy. If we inqured his papers published during his study in Standford Universtiy by inputting the author's name "Yao Hong" with the address "Stanford Univ" as research keywords, we would miss a lot of his papers, but if we input the author's name "Yao H" with the address "Stanford Univ" as research keywords, we may find a lot of papers that were not published by him. For example, authors named as "YAO Hai", "YAO Heng" or "YAO Hongjiang" were also indicated by "Yao H” , which brought 
great trouble to the search. In order to find papers published by each scholar as many as possible and ensure the accuracy of research results, without mixing papers published by other scholars with the same name, we tried a lot of methods to ensure high quality of the results. For example, adding the name of tutor as search keyword, or inputting the school name in addition to university name as search keywords.

To sum up, major retrieval methods for searching for papers published by returned scholars are as follows:

(1) The author's name (abbreviation) + tutor's name (abbreviation);

2) The author's name (abbreviation) + address (university name + school/department name)

(3) The author's name (abbreviation) + address + publication time

Finally, 567 papers published by these 73 returned scholars in the United States and 1314 published after their returning were searched. To classify by technical fields, these 73 scholars can be classified into 6 categories: general biology and medicine, nano technology (including nano-materials and devices), computer science and electronic technology, fundamental physics, synthetic and catalytic chemistry, environmental protection. Among them, most scholars (36) were engaged in biological and medical research. 16 scholars were engaged in nano technological research. These two categories accounted for $71.2 \%$ of the total samples. For other subjects, 4 cholars were engaged in computer science and electronic technology, 8 in fundamental physics, 6 in synthetic and catalytic chemistry and 3 in environmental protection. The distribution of technical fields is shown in Figure 1.

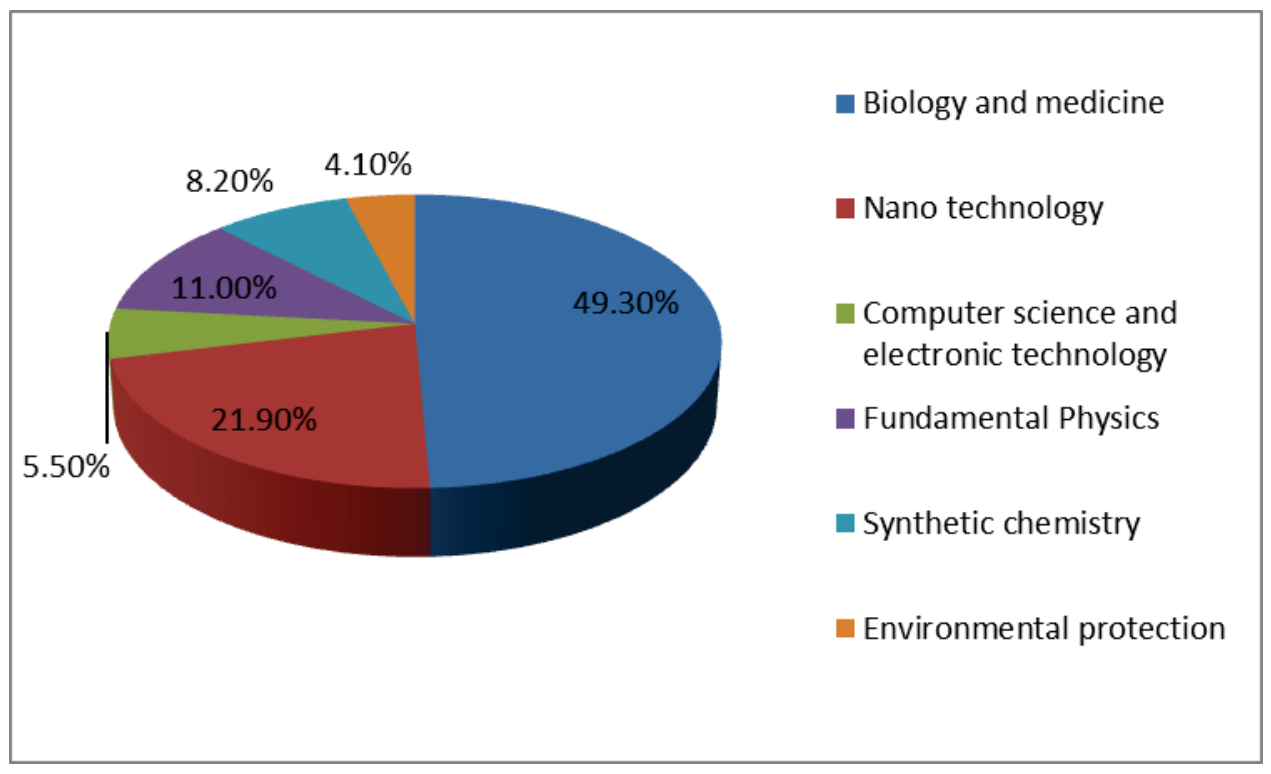

Figure 1 The distribution of returned scholars by technical fields

(2) Judgment methods of the same or similar academic subjects published by scholars before and after the returning

Academic subjects of returned scholars were measured by the titles, keywords, research directions and other information of papers published by them. In this paper, key words were selected the as measurement indexes. Keywords are core words of a paper, reflecting the research object, theme, ideas and methods of a paper. Therefore, two papers with the same or similar keywords will have similar academic subject, and this similarity will be higher with the increase of same or similar keywords.

The judgment of similarity was difficult, as it was difficult to judge how similar two key words would be to describe the same content. The same keyword is the simplest criteria, but its scope is too narrow, which will rule out a lot of papers with the same contents. For example, a scholar studies "two-dimensional material", a hot spot in the field of nano-materials in recent years, which is also expressed as "two-dimensional material", "two-dimensional materials", "two-dimensional gel electrophoresis" in papers he published. However, if the same keyword is selected as screening criteria, other keywords of the same meaning will be judged to express different technical contents, 
which is clearly not the fact. Therefore, it is necessary to propose a method to reflect the similarity of keywords.

In this paper, keywords with the same roots were considered to be similar, and keywords that had the same important roots were regarded as the same kind of keywords. For example, "nanoppapers" and "gold nanoppapers" expressed the same academic subject. And the function was automatically realized through setting program. The core of the algorithm was to extract roots of keywords by splitting a keyword into word bank for repeating words matching, including complete matching, and prefix and suffix matching. And the word of high repetition frequency was the root, as shown in figure 2. Two keywords "nonhistone chromosomal-proteins" and "nuclear phosphoprotein" were identified as keywords related to "protein" by adopting this method, as they were related to the study of protein.

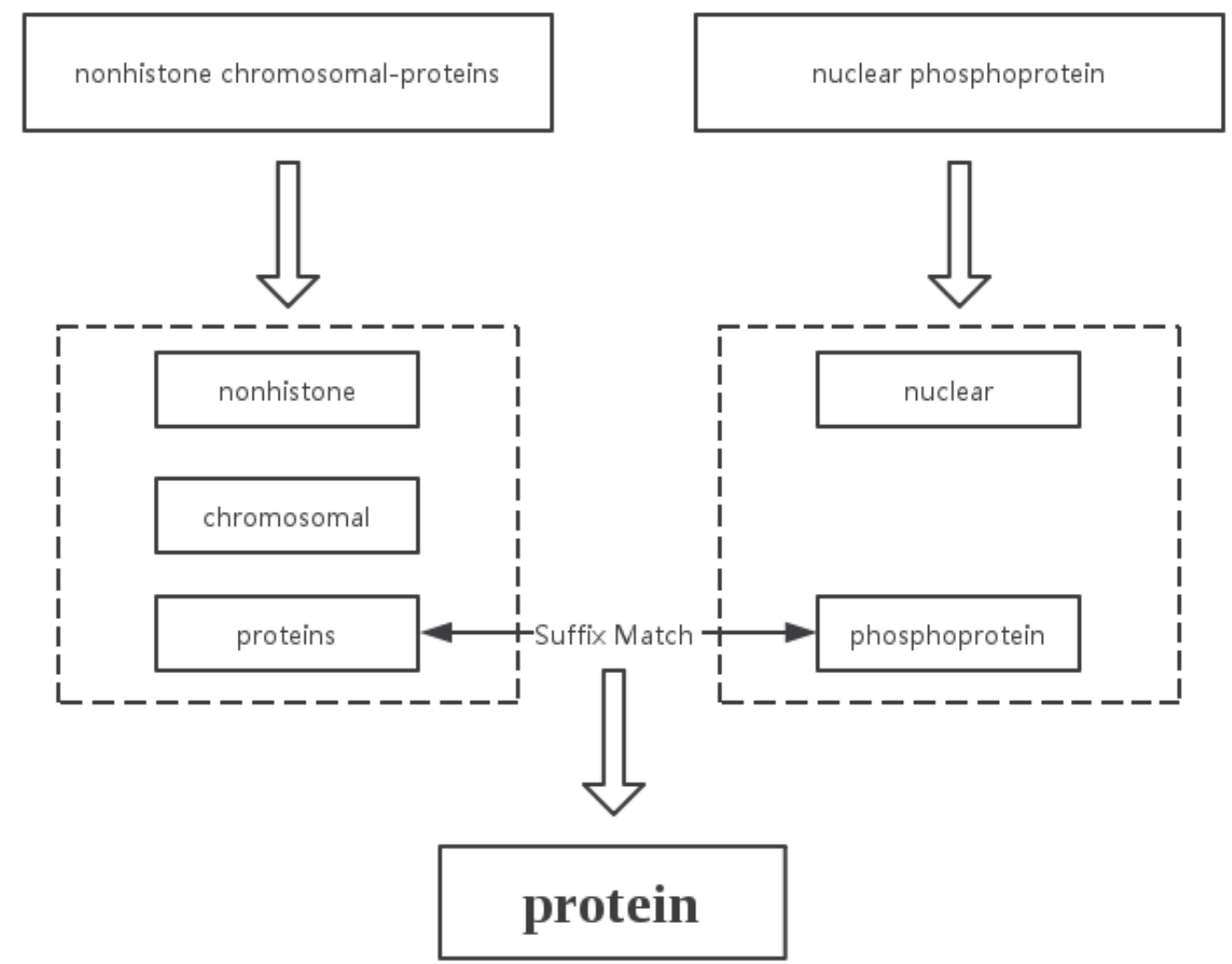

Figure 2 Schematic diagram of root extraction

The number of similar keywords was adopted as a measure standard of approximation degree of academic subjects. The more the similar keywords were, the higher the academic subjects of papers were related to researches conducted in the United States. Given that a paper usually had 6-8 keywords, if there were more than 3 similar keywords in a paper, the paper was considered to have academic subject same or highly similar to those published in the United States; if there were 1 to 3 similar keywords, then the paper had academic subject related to but not highly similar to the one published in the United States; if there was no similar keyword, it could be considered that the paper studied on a new subject.

Based on the number of similar keywords, knowledge transfer and innovation was divided into three different patterns. If the academic subjects of papers published after the returning were the same or highly similar to those published in the United States, it could be considered that returned scholars transferred knowledge from the United States to China mainly through study, and this pattern was defined as study-type innovation. If the paper had academic subject related to but not highly similar to the one published in the United States, indicating returned scholars worked on the academic subject not only through study, but also his innovation, so the pattern was defined as leading-type innovation. If the paper has academic subject completely unrelated to the one published in the United States, the paper was considered to be published completely by innovation which went beyond established 
knowledge, so the pattern was defined as breakthrough-type innovation. Relevant definitions are shown in Figure 3.

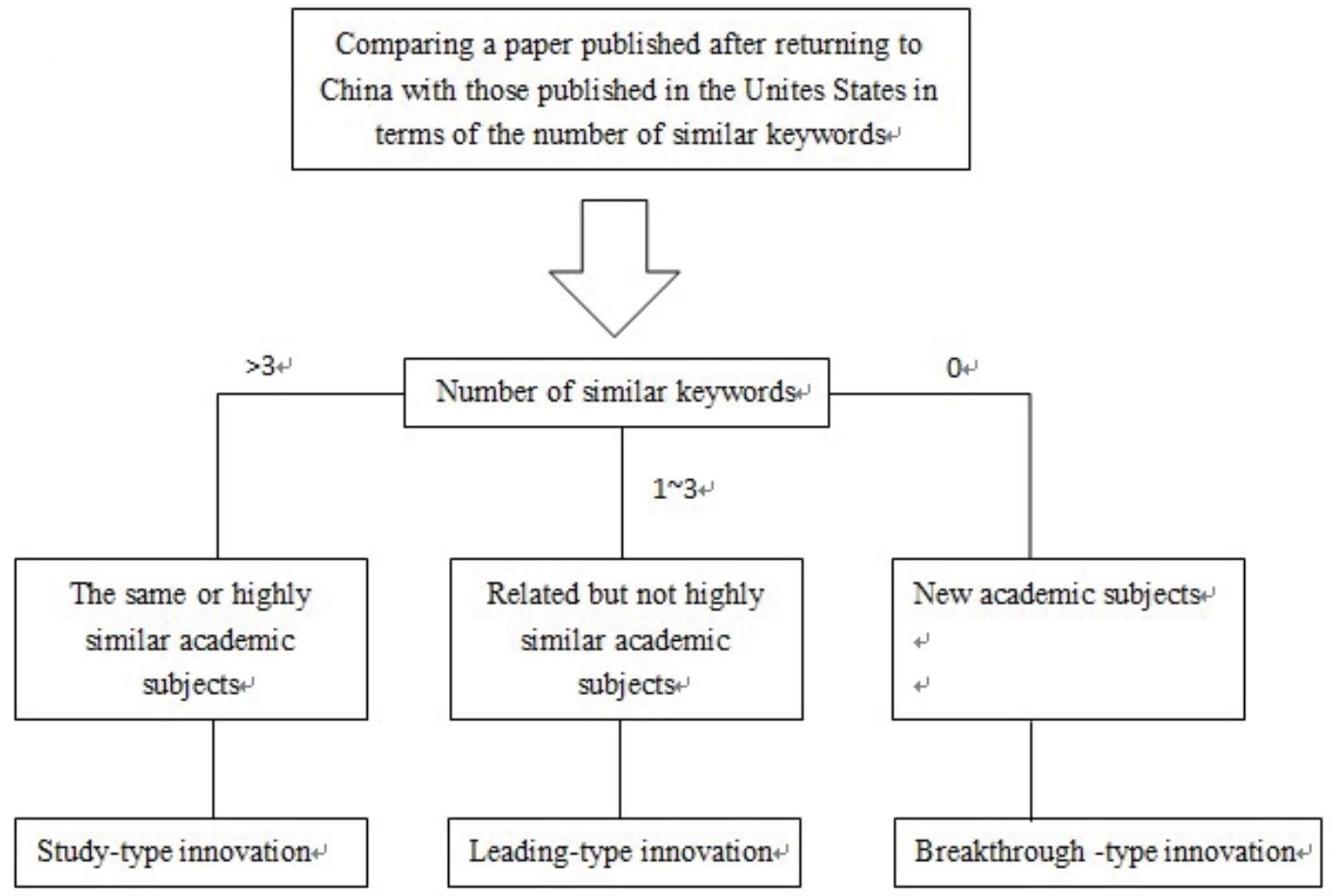

Figure 3 Knowledge transfer and innovation paternss based on the same or similar academic subjects

\section{Results and discussion}

This paper examined different characteristics of three patterns from the perspective of the quantity and quality of papers. The number of papers reflected scientific output ability of scholars, and the quality of papers reflected their research level and innovation quality. According to statistical data, 142 of 1314 papers published by returned scholars belonged to study-type innovation papers, accounting for $10.8 \%$ of all papers; 686 belonged to leading-type innovative papers, making up $52.2 \%$; and 486 belonged to breakthrough-type innovative papers, accounting for $37 \%$, indicating that scholars usually continued to work on previous researches after returning back to China; some worked on new academic subjects and published research results. Also, a small number of scholars continued to carry out researches based on overseas researches.

In addition, average annual citation was also adopted as criteria for evaluating the quality of papers, finding that the quality of three innovation patterns also differed. The results of paired test showed that on the whole, there was no difference between study-type innovation and leading-type innovation papers in quality, but their quality are significantly higher than the quality of breakthrough-type innovation papers, suggesting that scholars should be encouraged to introduce advanced knowledge from abroad. The results are shown in table 1.

Table 1 Comparison among papers of three different modes in terms of citation

\begin{tabular}{|r|c|c|c|}
\hline & $\begin{array}{c}\text { Study-type } \\
\text { leading-type }\end{array}$ & $\begin{array}{c}\text { Study-type vs } \\
\text { breakthrough-type }\end{array}$ & $\begin{array}{c}\text { Leading-type } \\
\text { breakthrough-type }\end{array}$ \\
\hline $\mathrm{t}$ & $0.38(0.97)$ & $1.27(3.28)$ & $0.89(3.76)$ \\
test & & & \\
\hline
\end{tabular}

Note: the data outside brackets refer to mean difference of the quality between two groups of papers, $t$ value inside brackets denote statistics, the absolute value greater than 2 indicating significant difference. 
We further investigated the number and quality of different modes of papers in various technical fields. In terms of the quantity, different from other fields, breakthrough-type innovation papers accounted for up to $59.6 \%$ of all papers in biological technology, and other fields were dominated by leading-type innovation papers as shown in figure 3. This may be because biotechnology field involved wide range of researches, such as large number of genes, proteins and signaling pathways, which indirectly encouraged scholars to make new attempts.

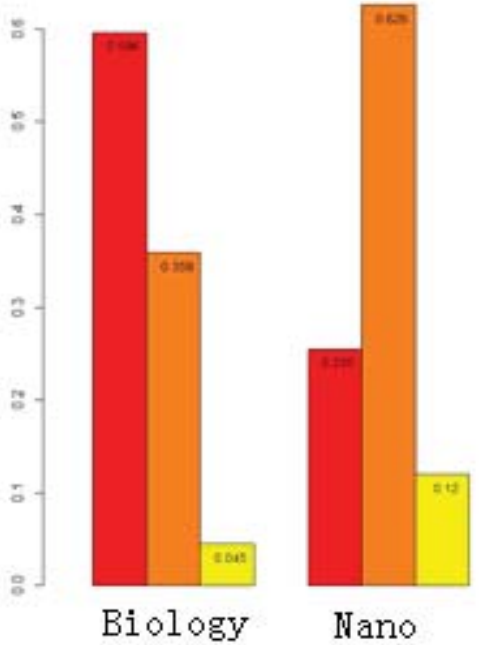

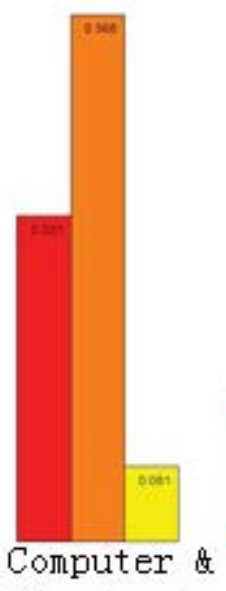

Electronics

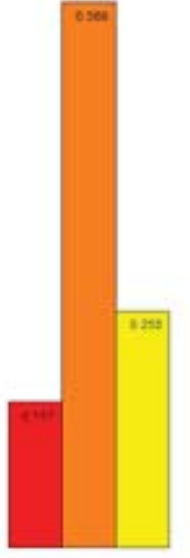

Physics

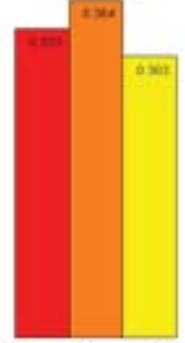

Synthetic Chemistry

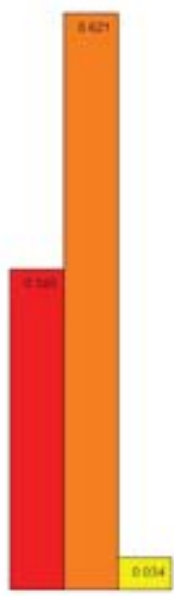

Environment

Figure. 4 Distribution of different types of papers in different research fields

Note: red, orange and yellow bars indicate breakthrough-type innovation, leading-type innovation and study-type innovation papers, respectively.

In view of the quality of papers, different papers in various technical fields also showed divergent characteristics. Three types of papers published by scholars engaged in biotechnology and fundamental physics showed no significant difference in quality after they returned back to China. Both of these two disciplines belong to basic research. Among papers published by scholars working on nano and environmental protection technology, leading-type innovation papers had the highest quality; and in computer and electronics as well as synthetic chemistry industry, study-type innovation papers had the highest quality, demonstrating there was a significant gap between China with the United States in in these two fields, as shown in table 2.

Table 2 Paired $t$ test on the quality of different types of papers in various fields

\begin{tabular}{|l|l|l|l|l|l|l|}
\hline & Biology & Nano & $\begin{array}{l}\text { Computer \& } \\
\text { electronics }\end{array}$ & $\begin{array}{l}\text { Fundamental } \\
\text { physics }\end{array}$ & $\begin{array}{l}\text { Synthetic } \\
\text { chemistry }\end{array}$ & $\begin{array}{l}\text { Environmental } \\
\text { protection }\end{array}$ \\
\hline $\begin{array}{l}\text { Study-type vs } \\
\text { leading-type }\end{array}$ & $0.69(0.84)$ & $0.33(0.63)$ & $1.95(1.75)$ & $-0.14(-0.06)$ & $1.36(1.81)$ & $-2.09(-1.96)$ \\
\hline $\begin{array}{l}\text { Leading-type vs } \\
\text { breakthrough-type }\end{array}$ & $0.49(1.28)$ & $0.74(2.02)$ & $0.48(0.82)$ & $-3.78(-0.80)$ & $0.33(0.89)$ & $2.16(3.05)$ \\
\hline $\begin{array}{l}\text { Study-type vs } \\
\text { breakthrough-type }\end{array}$ & $1.88(1.50)$ & $1.07(1.90)$ & $2.43(2.21)$ & $-3.92(-0.82)$ & $1.69(2.32)$ & $0.07(0.09)$ \\
\hline
\end{tabular}

Note: minus indicates that the quality of paper in front of "vs" is lower than that of another one

\section{Conclusions}

This paper investigated the patterns and characteristics of transnational knowledge transfer and innovation based on academic subjects. A novel keyword similarity algorithm was proposed which extracted root to mine similar keywords. And according to the amount of similar keywords, patterns of knowledge transfer and innovation are classified into three different types. If there were more than 3 similar keywords in a paper, the paper was considered to have academic subject same or highly similar to those published in the United States, so it could be considered that returned scholars 
transferred knowledge from the United States to China mainly through study, and this pattern was defined as study-type innovation; if there were 1 to 3 similar keywords, then the paper had academic subject related to but not highly similar to the one published in the United States, the pattern was defined as leading-type innovation; if there was no similar keyword, it could be considered that the paper studied on a new subject, so the pattern was defined as breakthrough type innovation.

The statistical results show that breakthrough-type innovation has the largest number among these three patterns, followed by leading-type innovation and study-type innovation. And the research quality of study-type innovation and leading-type innovation is much better than the quality of breakthrough-type innovation in most cases. The results prove that today the transnational knowledge transfer has been growing more important in pushing knowledge innovation made by scholars returned from overseas

\section{References}

[1] Andrea Fosfuri, Massimo Motta, Thomas Rønde. Foreign direct investment and spillovers through workers' mobility[J]. Journal of International Economics. 2001， 53(1):205-222

[2] Allan M. Williams. International labor migration and tactic knowledge transactions: a multi-level perspective [J]. Global Networks. 2007, 7(1) :29-50.

[3] Michaela Trippl, Gunther Maier. Knowledge Spillover Agents and Regional Development, Innovation, Growth and Competitiveness, Advances in Spatial Science, 2011: 91-111.

[4]Xuguang Nan. Talent flow, knowledge spillover and regional development:A dynamic knowledge connection model[J]. Technology and economy,2009,03:24-27.

[4] Nan Xuguang Talent Mobility, Knowledge Spillover and Regional Development: a Dynamic Knowledge Linking Model [J]. Technology and Economy, 2009,03:24-27.

[5] Simon Commander, Mari Kanganiemi, Alan L.Winters. The Brain Drain: A Review of Theory and Facts. Brussels Economic Review, 2004, 47: 29-44.

[6] Manon D.D. Santos, Fabien P. Vinay. Migration as a Source of Growth: The Perspective of a Developing Country. Journal of Population Economics, 2003, 16: 161-175.

[7] Lynne G. Zucker, Michael R.Darby. Movements of Star Scientists and Engineers and High-Tech Firm Entry, 2006, NBER Working Paper No. 12172, National Bureau of Economic, Research, Cambridge (MA).

[8] Ou Dai and Xiaohui Liu. Returnee Entrepreneurs and Firm Performance in Chinese High-technology Industries. International Business Review,2009, 18: 373-386.

[9] Xiaohui Liu, et al. Returnee Entrepreneurs , Knowledge Spillovers and Innovation in High-tech Firms in Emerging Economies. Journal of International Business Studies, 2010,41: 1183-1197.

[10] Igor Filatotcheva, et al. Knowledge spillovers through human mobility across national borders: Evidence from Zhongguancun Science Park in China. Research Policy, 2011 40: 453-462 